\title{
CARDIOVASCULAR SYSTEM MODELLING OF HEART-LUNG INTERACTION DURING MECHANICAL VENTILATION
}

\author{
Bram W. Smith ${ }^{1}$, Steen Andreassen ${ }^{1}$, Geoffrey M. Shaw ${ }^{2}$, Stephen E. Rees ${ }^{1}$ and J. Geoffrey Chase ${ }^{3}$ \\ ${ }^{1}$ Centre for Model-based Medical Decision Support, Aalborg University, Aalborg, Denmark \\ ${ }^{2}$ Centre for Bio-Engineering, Christchurch Hospital Dept of Intensive Care, \\ Christchurch, New Zealand \\ ${ }^{3}$ Centre for Bio-Engineering, Department of Mechanical Engineering, University of \\ Canterbury, Christchurch, New Zealand
}

\begin{abstract}
Choosing suitable ventilation strategies for critically ill patients with lung disorders involves considering the difficult and poorly understood trade-off between achieving adequate ventilation, while maintaining suitable perfusion. This study presents a minimal cardiovascular system model that includes variations in pulmonary vascular resistance during mechanical ventilation. The model is shown to capture transient haemodynamics from experimentally measured data. It also enables investigation into the effects of time varying resistance on pulmonary haemodynamics. The study shows the potential usefulness of this model in a tool to assist clinical staff in optimising ventilation pressures while maintaining adequate pulmonary perfusion. Copyright (c) 2006
\end{abstract}

Keywords: Biomedical systems, Physiological models, Dynamic modelling, Dynamic models, Lumped constant models.

\section{INTRODUCTION}

Although the lungs and the circulation system are usually simulated independently, the interaction between them has significant consequences for both systems. One important example of this is the interaction between lung pressures and pulmonary haemodynamics in critically ill patients with lung disorders. For example, patients suffering from acute respiratory distress syndrome (ARDS), or post cardiac surgery patients, require ventilation at high pressures to increase lung ventilation and improve gas exchange (Claxton et al., 2003; Dyhr et al. 2002). However, these high pressures can also cause a reduction in pulmonary perfusion, which can have a negative impact on gas exchange, as well as reducing cardiac output (Parrillo and Dellinger, 2002). The trade-off between achieving adequate ventilation, while maintaining adequate pulmonary perfusion, is an important consideration when treating intensive care patients.
High ventilator pressures affect circulation in a number of ways (West, 2005; Parrillo and Dellinger, 2002). Increased pressure acting on the outside of the heart limits ventricle filling. Increased pressure on the large pulmonary arteries and veins causes a reduction in the pulmonary circulation blood volume. Increased pleural pressure and lung volume impedes blood flow through the capillaries, increasing the pulmonary vascular resistance.

Pulmonary vascular resistance $\left(\mathrm{R}_{\mathrm{pul}}\right)$ is generally defined as:

$$
\mathrm{R}_{\mathrm{pul}}=\frac{\mathrm{P}_{\mathrm{pa}}-\mathrm{P}_{\mathrm{pu}}}{\mathrm{CO}}
$$

where the pressure drop across the pulmonary circulation is defined as the pulmonary artery pressure $\left(\mathrm{P}_{\mathrm{pa}}\right)$ minus the pulmonary venous pressure $\left(\mathrm{P}_{\mathrm{pu}}\right)$, and cardiac output (CO) represents the average blood flow through the pulmonary circulation. This resistance can vary during both the cardiac cycle and 
the respiratory cycle by two main mechanisms (West, 2005). Firstly, the cross-sectional area of a capillary, and thus the resistance, is dependent on the pressure drop across the capillary wall. A decreased blood pressure in the capillary, or a reduced pleural pressure acting on the outside of the capillary, will cause the capillary to expand and its resistance to be reduced. Secondly, due to hydrostatic effects, the blood pressure in the capillaries is lower at the highest point in the lungs than at the lowest point. A pressure increase in the pulmonary artery can cause capillaries to become recruited, thus reducing the total pulmonary resistance. Both of these effects are largely dependent on the pressure difference between the pulmonary artery and the pleural pressure.

There are many models of the circulation system and the respiratory system in the literature (Beyar et al. 1987; Ursino, 1999; Barbini et al., 2003). However, there are very few models that simulate the impact of changes in lung pressure and volume on haemodynamics, especially relating to pulmonary vascular resistance. Probably the most comprehensive compartmental cardiopulmonary interaction models are described by Liu et al. (1998) and $\mathrm{Lu}$ et al. (2001). Both these models combine detailed circulation system and respiratory system models. Liu et al. (1998) divides the pulmonary vascular resistance into three different resistances that are dependent on pleural pressure, alveolar volume and capillary volumes. Lu et al. (2001) uses a much simpler definition where pulmonary resistance is dependent on lung volume. However, in both cases, these models are not verified against experimentally measured pulmonary artery pressure, which is an important factor in pulmonary perfusion.

Scharf et al. (1980) have carried out experimental studies where they measured pulmonary and systemic artery pressures and flow rates simultaneously with pleural pressure variations during mechanical ventilation. If the respiratory drive has been suppressed, it can be assumed that thoracic cavity compliance remains constant during mechanical ventilation. Under these conditions, according to West (2005), pleural pressure, lung volume and pulmonary vascular resistance should all vary proportionally to one another. So during the mechanical inspiration, pulmonary vascular resistance will increase as pleural pressure increases and visa versa.

This research presents a model based investigation into the affect of mechanical ventilation on pulmonary haemodynamics. All of the interaction mechanisms discussed above are considered, with specific focus on the effects of variations in pulmonary vascular resistance during respiration. A minimal cardiovascular system model, described by Smith et al. (2004a), is used to simulate experimentally measured haemodynamic changes during mechanical ventilation (Scharf et al. 1980). A simple proportional relationship is defined between the pleural pressure and the pulmonary vascular resistance. The investigation focuses on the importance of including a time varying pulmonary vascular resistance and the ability of this simple model to capture the measured haemodynamic trends in the experimental data.

\section{METHOD}

\subsection{The cardiovascular system model}

The minimal cardiovascular system model used in this study, shown schematically in Figure 1, is defined in detail in Smith et al (2004a). The systemic circulation is made up of two chambers representing the vena-cava (vc) and the aorta (ao), connected by a resistor to simulate the net systemic resistance $\left(\mathrm{R}_{\mathrm{sys}}\right)$. Similarly, the pulmonary circulation is simulated as the pulmonary artery (pa) chamber connected to the pulmonary vein (pu) chamber by the pulmonary vascular resistance $\left(R_{\text {pul }}\right)$.

The two central chambers represent the left and right ventricles (lv and rv). The atria are not included in the model for simplicity. Resistances at the inlet and exit of the right ventricle account for pressure drops of blood flow entering from the systemic circulation through the tricuspid valve (tc) and exiting through the pulmonary valve (pv) into the pulmonary circulation. For the left ventricle, resistances are simulated acting on blood flow entering from the pulmonary circulation through the mitral valve (mt) and exiting through the aortic valve (av) into the systemic circulation. The pleural (pl) pressure defines the pressure inside the thoracic cavity and acts on the outside of the heart and pulmonary circulation. Respiration is simulated by cyclically varying the pleural pressure $\left(\mathrm{P}_{\mathrm{pl}}\right)$.

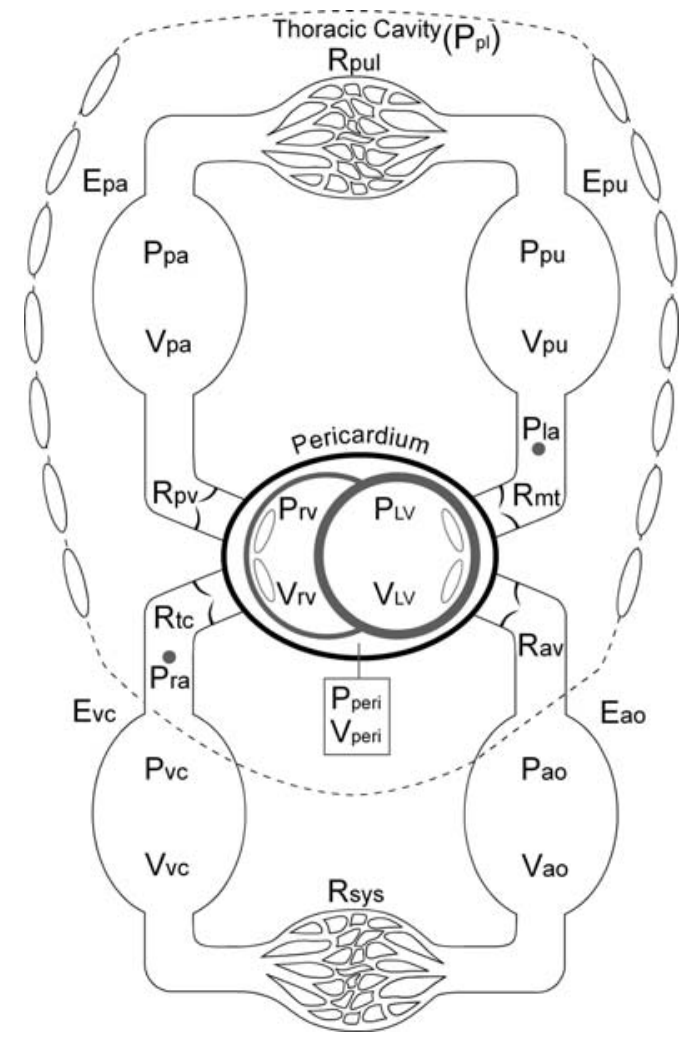

Fig. 1. Diagram of the cardiovascular system model used in this study. 


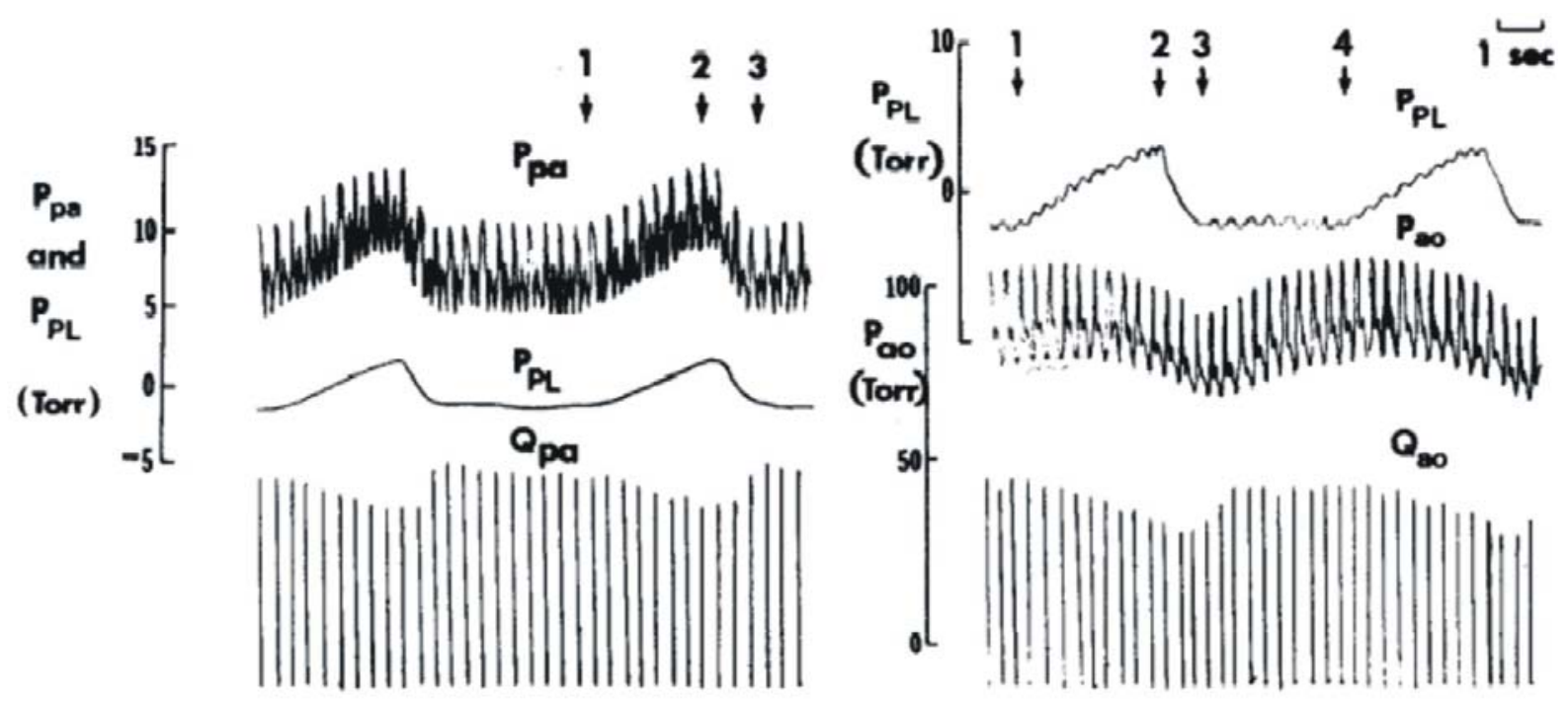

Fig. 2. Experimentally measured pulmonary and systemic artery pressures $\left(\mathrm{P}_{\mathrm{pa}}\right.$ and $\left.\mathrm{P}_{\mathrm{ao}}\right)$ and flow rates $\left(\mathrm{Q}_{\mathrm{pa}}\right.$ and $\mathrm{Q}_{\mathrm{ao}}$ ) during mechanical ventilation, as shown by the variations in pleural pressure $\left(\mathrm{P}_{\mathrm{pl}}\right)$ (Scharf et al., 1980).

Tables 1, 2 and 3 list the generic model parameters used by Smith (2004b). The 2 ventricles are divided into 3 walls, the left ventricle wall (lvf), the right ventricle wall (rvf) and the septum wall (spt). During ventricle relaxation, the pressure volume relationships of these walls are defined by elastance $\left(\mathrm{P}_{0}\right)$, the non-linearity $(\lambda)$ and the volume at zero pressure $\left(\mathrm{V}_{0}\right)$. During ventricular contraction, the pressure volume relationships of these walls are defined by the contractility $\left(\mathrm{E}_{\mathrm{es}}\right)$ and the volume at zero pressure $\left(\mathrm{V}_{\mathrm{d}}\right)$. The same non-linear pressure volume relationship used for the relaxed ventricles is used for the pericardium (pcd).

\subsection{The experimental data}

The experiments by Scharf et al. (1980) were carried out on anaesthetized dogs on positive pressure ventilation. Systemic arterial pressure $\left(\mathrm{P}_{\mathrm{ao}}\right)$ was measured in the thoracic aorta using a femoral artery catheter. A pulmonary artery catheter was used to get the pulmonary artery pressure $\left(\mathrm{P}_{\mathrm{pa}}\right)$. Square wave

Table 1. Mechanical properties of the heart and circulation system (Smith, 2004b).

\begin{tabular}{|c|c|c|c|c|c|}
\hline Param & $\begin{array}{l}\mathbf{E}_{\text {es }} \\
\mathrm{Pa} / \mathrm{m}^{3} \\
\left(\times 10^{6}\right)\end{array}$ & $\begin{array}{l}\mathbf{V}_{\mathbf{d}} \\
\mathrm{m}^{3} \\
\left(\times 10^{-6}\right)\end{array}$ & $\begin{array}{l}\mathbf{V}_{\mathbf{0}} \\
\mathrm{m}^{3} \\
\left(\times 10^{-6}\right)\end{array}$ & $\begin{array}{l}\lambda \\
\mathrm{m}^{-3} \\
\left(\times 10^{3}\right)\end{array}$ & $\begin{array}{l}\mathbf{P}_{\mathbf{0}} \\
\mathrm{Pa}\end{array}$ \\
\hline lvf & 100 & 0 & 0 & 33 & 10 \\
\hline rvf & 54 & 0 & 0 & 23 & 10 \\
\hline spt & 6500 & 2 & 2 & 435 & 148 \\
\hline pcd & - & - & - & 30 & 66.7 \\
\hline VC & 1.3 & 2830 & - & - & - \\
\hline pa & 72 & 160 & - & - & - \\
\hline $\mathrm{pu}$ & 1.9 & 200 & - & - & - \\
\hline ao & 98 & 800 & - & - & - \\
\hline
\end{tabular}

electromagnetic flow probes were placed around the ascending aorta and the main pulmonary artery to measure the systemic arterial and pulmonary arterial flow rates $\left(\mathrm{Q}_{\mathrm{ao}}\right.$ and $\left.\mathrm{Q}_{\mathrm{pa}}\right)$ respectively. Pleural pressure was measured using a 0.25 inch diameter cannula placed into the right hemothorax at the midaxillary line. Figure 2 shows the experimentally measured variations in these values during 2 mechanical ventilation breaths.

Very little information about the cardiovascular system mechanical properties of the studied dogs can be gained from the publication (Scharf et al., 1980). It is known that the heart rate remained relatively constant during the procedure at approximately 160 beats per minute. The respiration rate was held at 10 breaths per minute and tidal volume was constant at $300 \mathrm{ml}$. To verify that the minimal model captures the experimental dynamics, despite the lack of specific information, the generic model parameter values listed in Tables 1, 2 and 3, from Smith (2004b), are used. The simulated heart rate is set to 160 beats per minute and pleural pressure is varied cyclically at 10 breaths per minute.

Table 2. Resistances in the circulation system (Smith, 2004b).

\begin{tabular}{ll}
\hline Param & $\begin{array}{l}\text { Resistance } \\
\text { Pa.s } / \mathrm{m}^{3} \\
\left(\times 10^{-6}\right)\end{array}$ \\
\hline $\mathrm{mt}$ & 6.1 \\
$\mathrm{av}$ & 2.75 \\
$\mathrm{tc}$ & 1 \\
$\mathrm{pv}$ & 1 \\
$\mathrm{pul}$ & 9.4 \\
sys & 170 \\
\hline
\end{tabular}

Table 3. Additional model parameters (Smith, 2004b).

\begin{tabular}{ll}
\hline Parameter & Value \\
\hline Heart rate $(\mathrm{HR})$ & 160 beats $/ \mathrm{min}$ \\
Blood volume $\left(\mathrm{V}_{\text {tot }}\right)$ & $5.5 \times 10^{-3} \mathrm{~m}^{3}$ \\
Pleural pressure $\left(\mathrm{P}_{\mathrm{pl}}\right)$ & $-1 \mathrm{mmHg}$ \\
\hline
\end{tabular}


The magnitude and contour of the variation in pleural pressure used in the model simulation was estimated by eye from Figure 2. The pleural pressure is set to vary between $-1 \mathrm{mmHg}$ and $1 \mathrm{mmHg}$. The variation in pulmonary vascular resistance used in the model is defined by the following simple linear relationship:

$$
\mathrm{R}_{\text {pul }}(\mathrm{t})=\mathrm{C}_{\mathrm{R}} \times \mathrm{P}_{\mathrm{pl}}(\mathrm{t})+\mathrm{R}_{\text {pul }, 0}
$$

where $R_{p u l, 0}$ defines the resistance at zero pleural pressure and $C_{R}$ defines the gain of the relationship between pleural pressure and pulmonary resistance. For these simulations $C_{R}$ is set to $7 \times 10^{6} \mathrm{~Pa} . \mathrm{s} / \mathrm{m}^{3}$ and $\mathrm{R}_{\mathrm{pul}, 0}$ is set to $16.5 \times 10^{6} \mathrm{~Pa} . \mathrm{s} / \mathrm{m}^{3}$. This definition means that at end expiration, when the pleural pressure is $-1 \mathrm{mmHg}, \mathrm{R}_{\mathrm{pul}}(\mathrm{t})$ is equal to the base value in Table 2 . When the pleural pressure increases to a maximum value of $1 \mathrm{mmHg}, \mathrm{R}_{\text {pul }}(\mathrm{t})$ increases to 2.5 times the base value. These values were chosen by manually increasing the variation in $\mathrm{R}_{\text {pul }}(\mathrm{t})$ until the simulated profile of $\mathrm{P}_{\mathrm{pa}}$ was similar to the experimental results in Figure 2.

\section{RESULTS}

Figure 3 shows the results using the cardiovascular system model to simulate the experiment carried out by Scharf et al., (1980). Figure 4 shows the same simulation results, but with the pulmonary vascular resistance $\left(R_{\text {pul }}\right)$ held constant. Values of pleural pressure $\left(\mathrm{P}_{\mathrm{pl}}\right)$, systemic artery pressure $\left(\mathrm{P}_{\mathrm{ao}}\right)$ and pulmonary artery pressure $\left(\mathrm{P}_{\mathrm{pa}}\right)$ are labeled in the same way in Figures 2, 3 and 4. The measured flow in the pulmonary artery $\left(\mathrm{Q}_{\mathrm{pa}}\right)$ in Figure 2 correlates to the simulated flow through the pulmonary valve $\left(\mathrm{Q}_{\mathrm{pv}}\right)$ in Figures 3 and 4. Likewise, the measured flow in the aorta $\left(\mathrm{Q}_{\mathrm{ao}}\right)$ in Figure 2. correlates to the simulated flow through the aortic valve $\left(\mathrm{Q}_{\mathrm{ao}}\right)$ in Figures 3 and 4.
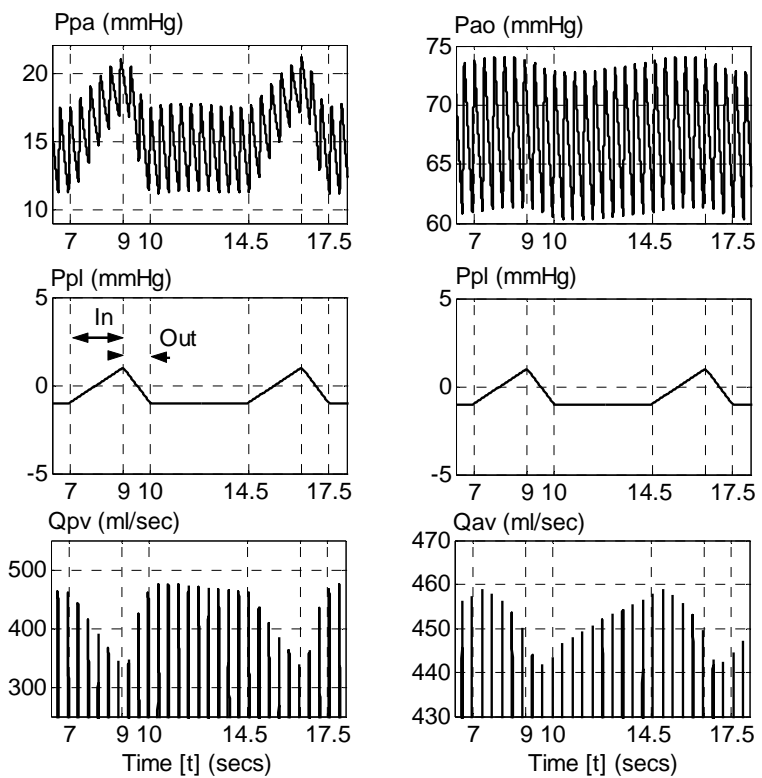

Fig. 3. Cardiovascular system model simulations of mechanical ventilation with time varying pulmonary vascular resistance.
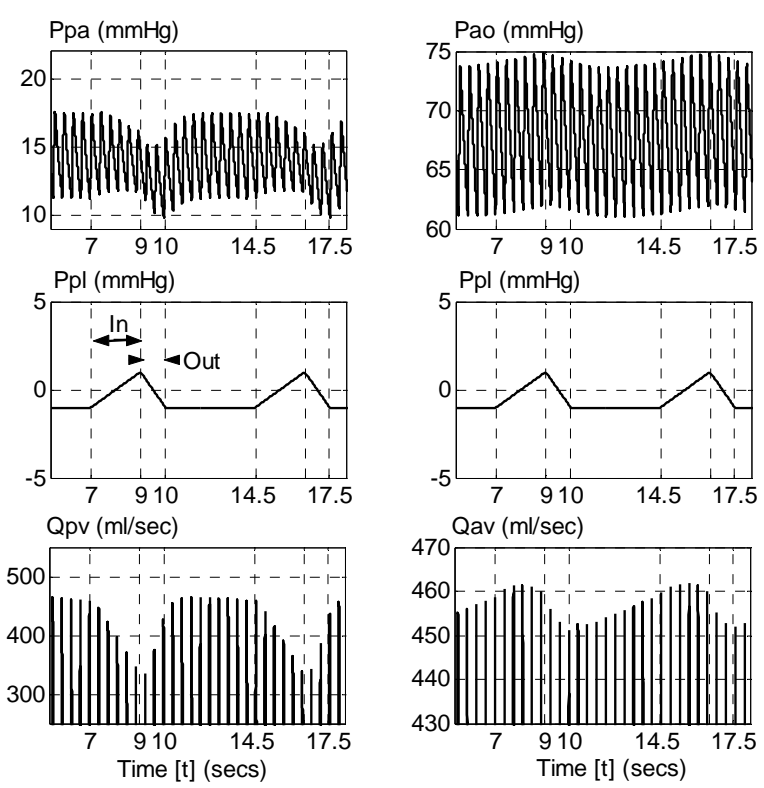

Fig. 4. Cardiovascular system model simulations of mechanical ventilation with constant pulmonary vascular resistance.

The simulation results with time varying pulmonary vascular resistance, shown in Figure 3, capture all of the main trends in the experimental results, shown in Figure 2. However, it was not possible to produce quantitative comparisons between the simulations and the experimental data, since there was not enough data available about the experiments. For example, the magnitudes of the flow rates in Figure 2 are not shown. Figure 4 shows that with resistance held constant, the cardiovascular system is not longer capable of capturing the variations in pulmonary artery pressure $\left(\mathrm{P}_{\mathrm{pa}}\right)$. However, if the pulmonary artery pressure variations are ignored, the trends in the remaining variables for both simulations roughly match the experimental data.

Figure 5 shows an enlarged view of the second breath in Figure 3 to more clearly show how the flow rate through the pulmonary artery $\left(\mathrm{Q}_{\mathrm{pv}}\right)$ and the aorta $\left(Q_{a v}\right)$ vary during a positive pressure inspiration. The pulmonary artery flow is seen to respond immediately at the start of inspiration ( $\mathrm{t}=14.5 \mathrm{secs}$ ) and reach a minimum at the end of inspiration $(t=16.5$ secs $)$. However, the effect of the inspiration on the flow through the aorta is not seen immediately, with an approximately 0.5 seconds lag behind the pulmonary artery response. This immediate response in pulmonary artery flow, and delayed response of aortic flow, can also be seen in the experimental measurements in Figure 2. 

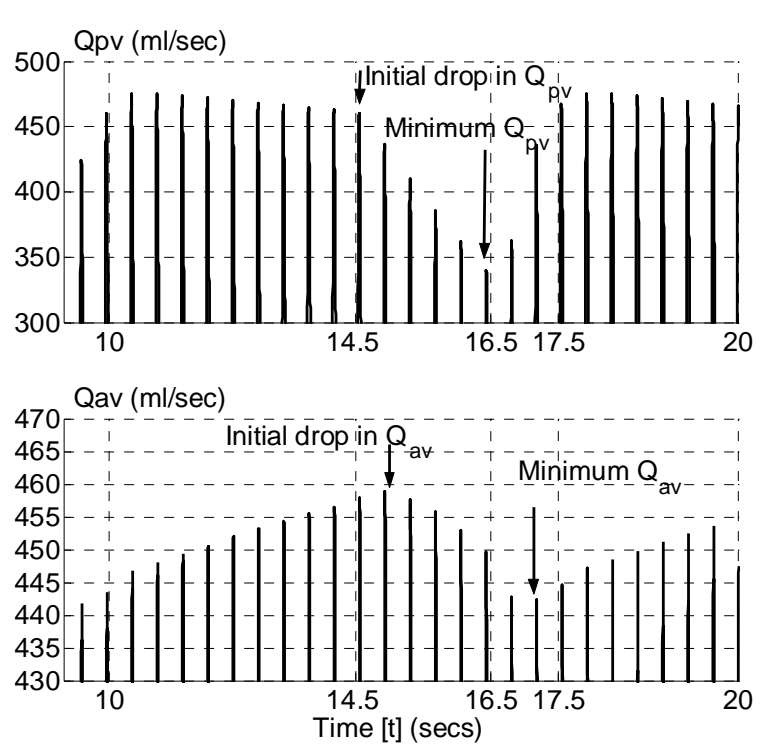

Fig. 5. Enlarged view of the second breath in Figure 3 showing that the variations in $\mathrm{Q}_{\mathrm{av}}$ due to inspiration lag behind those of $\mathrm{Q}_{\mathrm{pv}}$ by about 0.5 seconds.

\section{DISCUSSION}

The results show the ability of the model to simulate the variety of different mechanisms by which lung pressures affect haemodynamics. Although the experimental results used to validate the simulations are poor in quality, they clearly show the model captures the main trends. Increased pleural pressure during mechanical ventilation is shown to cause a reduction in the flows through both the pulmonary and systemic arteries as well as a drop in blood pressure $\left(\mathrm{P}_{\mathrm{ao}}\right)$.

The reduction in pulmonary artery flow $\left(\mathrm{Q}_{\mathrm{pv}}\right)$ is due to the increased pleural pressure during inspiration. This compresses the heart, causing a reduction in right ventricle filling and therefore an immediate reduction in flow into the pulmonary artery. This effect is reversed during expiration, where the pulmonary artery flow rapidly recovers to its initial value.

The reduction in systemic artery flow $\left(\mathrm{Q}_{\mathrm{av}}\right)$ is slightly delayed relative to the reduction in $\mathrm{Q}_{\mathrm{pv}}$, as shown in Figure 5. This delay occurs because the increase in pleural pressure actually causes a small rise in flow through the systemic artery as blood is pushed out of the pulmonary circulation. However, this rise is quickly overcome by the reduction in blood flow due to restrictions on pulmonary perfusion and the drop in pulmonary filling $\left(\mathrm{Q}_{\mathrm{pv}}\right)$. The flow rate in the aorta begins to increase again during expiration, but once again Figure 5 shows there is a delay between the onset of expiration and the beginning of an increase in flow rate.

In particular the results show the importance of including time varying pulmonary vascular resistance when simulating cardiopulmonary interaction. With time varying pulmonary vascular resistance included in the simulations, the increased pleural pressure during inspiration causes the pulmonary artery pressure to increase, as shown in Figure 3. This result could be misinterpreted as the pleural pressure simply compressing the pulmonary artery. However, if the pulmonary vascular resistance is held constant, Figure 4 shows that the pulmonary artery pressure actually decreases. This means that the rise in pulmonary artery pressure, seen in the experimental data during inspiration, is actually due to a rise in pulmonary vascular resistance during inspiration. The reduction in pulmonary artery pressure with constant resistance, as shown in Figure 4 , is most likely due to the reduced flow rate into the pulmonary artery $\left(\mathrm{Q}_{\mathrm{pv}}\right)$.

This is the first illustration known to the authors of a cardiovascular system model simulating transient changes in pulmonary artery pressure during mechanical ventilation. Although measuring pulmonary artery pressure is a relatively invasive procedure, requiring insertion of a pulmonary artery catheter (PAC), this procedure is currently carried out in many clinical institutions on critically ill patients. Other models were found to focus on simulating the dynamics of pressures and flow in the systemic artery. However, the simulations in Figures 3 and 4 show little difference in systemic artery dynamics between constant and time varying pulmonary resistance. These results show the importance of considering the pulmonary artery pressure changes when verifying a cardiopulmonary interaction model.

These results are achieved using a relatively small scale model compared to others in the literature. The presented model uses only two elastic chambers and one time varying resistance to define the pulmonary circulation. This is important when considering application of these models to the clinical setting where parameter identification techniques may be needed to create patient specific models (Hann et al., 2004). The number of parameters must be minimised to reduce the complexity of fitting to specific patient data.

\section{CONCLUSIONS}

The minimal cardiovascular system model presented is shown to accurately simulate experimentally measured transient haemodynamics due to cardiopulmonary interaction during mechanical ventilation. Previous models are more complex and have not been shown to simulate pulmonary artery pressure fluctuations. This study highlights an important link between variations in pulmonary vascular resistance and fluctuations in pulmonary artery pressure during respiration. The model shows potential for implementation in a diagnostics tool where it is necessary to simulate the effects of changes in respiratory pressures on a patient's circulation system. 


\section{REFERENCES}

Barbini P., G. Cevenini and G. Avanzolini (2003) Nonlinear Mechanisms Determining Expiratory Flow Limitation in Mechanical Ventilation: A Model-Based Interpretation, Annals of Biomedical Engineering, 31(8), pages 908-916

Beyar, R., M.J. Hausknecht, H.R. Halperin, F.C.P. Yin and M.L. Weisfeldt, (1987). Interaction between cardiac chambers and thoracic pressure in intact circulation. Am. J. Physiol. 22(253), H1240-H1252.

Claxton B.A., P. Morgan, H. Mckeague, A. Mulpur and J. Berridge (2003) Alveolar recruitment strategy improves arterial oxygenation after cardiopulmonary bypass. Anaesthesia. 58(2), page 111.

Dyhr T., N. Laursen and A. Larsson (2002) Effects of lung recruitment maneuver and positive end-expiratory pressure on lung volume, respiratory mechanics and alveolar gas mixing in patients ventilated after cardiac surgery. Acta Anaesthesiologica Scandinavica. 46(6) page 717.

Hann, C.E., J.G. Chase, G.M. Shaw, and B.W. Smith (2004) Identification Of Patient Specific Parameters For A Minimal Cardiac Model. Proc 26th International Conf of IEEE Engineering in Med and Biology Society. San Francisco, CA, pages 813-816.

Lu K, J.W. Clark, F.H. Ghorbel, D.L. Ware and A. Bidani (2001) A human cardiopulmonary system model applied to the analysis of the Valsalva maneuver. Am J Physiol Heart Circ Physiol. 281(6) pages H2661-79.

Liu C.H., S.C. Niranjan, J.W. Clark, K.Y. San, J.B. Zwischenberger and A. Bidani (1998) Airway mechanics, gas exchange, and blood flow in a nonlinear model of the normal human lung. $J$ Appl Physiol. 84 pages 1447-1469.

Parrillo, J.E. and R.P. Dellinger (2002) Critical Care Medicine, Principles of Diagnosis And Management In The Adult, 2nd Ed. St. Louis, Missouri, Mosby.

Scharf, S.M., R. Brown, N. Saunders and L.H. Gren (1980) Hemodynamic effects of positivepressure inflation. J. Appl. Physiol. 49(1) pages 124-31.

Smith B.W., J.G. Chase, R.I. Nokes, G.M. Shaw and G. Wake (2004a) Minimal haemodynamic system model including ventricular interaction and valve dynamics. Medical Engineering and Physics 26 pages 131-139

Smith B W (2004b) Minimal Haemodynamic Modelling of the Heart and Circulation for Clinical Application. PhD Thesis, Canterbury University, Christchurch, New Zealand.

Ursino, M. (1999). A mathematical model of the carotid baroregulation in pulsating conditions. IEEE Trans Biomed Eng, 46(4) pages 382-92.

West J.B. (2005) Respiratory physiology, The essentials. 7th Ed. Lippin Williams \& Wilkins, USA. 